\title{
Regionalization of precipitation characteristics in Iran's Lake Urmia Basin
}

Nasim Fazel ${ }^{1}$, Ronny Berndtsson ${ }^{2,3}$, Cintia Bertacchi $\mathrm{Uvo}^{3}$, Kaveh Madani ${ }^{4,5}$, and Bjørn Kløve ${ }^{1}$

${ }^{1}$ Water Resources and Environmental Engineering, Faculty of Technology, University of Oulu,

Oulu, Finland

${ }^{2}$ Center for Middle Eastern Studies, Lund University, Lund, Sweden

${ }^{3}$ Department of Water Resources Engineering, Lund University, Lund, Sweden

${ }^{4}$ Centre for Environmental Policy, Imperial College London, London, UK

${ }^{5}$ Department of Physical Geography, Stockholm University, Stockholm, Sweden

Corresponding author:

Nasim Fazel

Water Resources and Environmental Engineering

University of Oulu, Finland

Nasim.fazel@oulu.fi

+358503500801 


\section{Abstract}

Lake Urmia in northwest Iran, once one of the largest hyper saline lakes in the world, has shrunk by almost $90 \%$ in area and $80 \%$ in volume during the last four decades. To improve the understanding of regional differences in water availability throughout the region and to refine the existing information on precipitation variability, this study investigated the spatial pattern of precipitation for the Lake Urmia Basin. Daily rainfall time series from 122 precipitation stations with different record lengths were used to extract 15 statistical descriptors comprising $25^{\text {th }}$ percentile, $75^{\text {th }}$ percentile, and coefficient of variation for annual and seasonal total precipitation. Principal component analysis in association with cluster analysis identified three main homogeneous precipitation groups in the lake basin. The first sub-region (Group-1) includes stations located in the center and southeast, the second sub-region (Group-2) covers mostly northern and northeastern part of the basin, and the third sub-region (Group-3) covers the western and southern edges of the basin. Results of principal component (PC) and clustering analyses showed that seasonal precipitation variation is the most important feature controlling the spatial pattern of precipitation in the lake basin. The $25^{\text {th }}$ and $75^{\text {th }}$ percentiles of winter and autumn are the most important variables controlling the spatial pattern of the first rotated principal component explaining about $32 \%$ of the total variance. Summer and spring precipitation variations are the most important variables in the second and third rotated principal components, respectively. Seasonal variation in precipitation amount and seasonality are explained by topography and influenced by the lake and westerly winds that are related to the strength of the North Atlantic Oscillation. Despite using incomplete time series with different lengths, the identified sub-regions are physically meaningful. 
Keywords: Lake Urmia; Rainfall-generating systems; Spatial pattern; Principal component analysis; Homogeneous precipitation sub-regions; Iran.

\section{Introduction}

Lake Urmia, once one of the largest hyper saline lakes in the world, is located in northwest Iran, between the East and West Azerbaijan Provinces. The shallow lake and its satellite islands are protected by the Ramsar Convention on Wetlands of International Importance and comprise a UNESCO Biosphere Reserve. This terminal lake with a maximum surface area of $6100 \mathrm{~km}^{2}$ and maximum depth of 16 m (Delju et al. 2013) has shrunk dramatically since 1995 (Sima et al. 2013; Jalili et al. 2016) and it now holds less than $20 \%$ of its previous water volume and $12 \%$ of its original area (AghaKouchak et al. 2015).

Due to the socio-ecological importance of the Lake Urmia in the region, a great amount of research has dealt with Lake Urmia shrinkage addressing different aspects of it such as biodiversity, climate, hydrology and water resources, and environmental management (Abatzopoulos et al. 2006; Zarghami 2011; Babavalian et al. 2014; Alipour and Olya 2015; Hamzekhani et al. 2016). Climate change and variability, recognized as drivers of the lake's desiccation, have been the focus of many studies over the past decades. These studies, covering various time periods, have emphasized trends and temporal variabilities in precipitation and temperature. Precipitation trend analyses detected a declining temporal trend for annual total precipitation (Delju et al. 2013; Fathian et al. 2014) and an insignificant gradually decreasing trend in wet season precipitation (Tabari and Hosseinzadeh Talaee 2011; Delju et al. 2013). Studies dealing with temperature have found a significant warming trend for both seasonal and annual time scales in the region (Delju et al. 2013; Zohrabi et al. 2014). Spatial patterns and regionalization of 
precipitation have been, however, understudied in the Lake Urmia Basin, despite the usefulness of delineation of homogeneous rainfall regions in water resources planning and management.

A variety of techniques have been used to identify spatial patterns and homogeneous precipitation regions, including correlation analysis, principal component analysis (PCA), spectral analysis and, and cluster analysis (Saikranthi et al. 2013). PCA in association with cluster analysis is the most commonly used method in delineating spatial pattern and homogenous rainfall regions (Dinpashoh et al. 2004; Raziei et al. 2008; Modarres and Sarhadi 2011; Gocic and Trajkovic 2014). Some studies investigating precipitation characteristics at larger scales (i.e., Iran and western Iran) have identified northwest Iran as a distinct region with a different precipitation pattern from the rest of the country (Soltani et al. 2007; Modarres and Sarhadi 2011; Darand and Daneshvar 2014). Nevertheless, information on spatial characteristics of seasonal and annual precipitation in the Lake Urmia Basin is not readily available despite its critical role in the lake restoration and management efforts.

Most previous studies dealing with precipitation and its characteristics in the Lake Urmia Basin have used a limited number of stations (Delju et al. 2013; Fathian et al. 2014; Vaheddoost and Aksoy 2016). While a number of precipitation stations are available (more than 200 stations), the series are incomplete and have different time spans. To avoid loss of information by disregarding short or highly incomplete time series objectives of this study are 1) to analyze the spatial pattern of precipitation characteristics in the Lake Urmia Basin using all available precipitation data to avoid information loss; 2) to identify spatial distribution of annual and seasonal precipitation in the basin; and 3) to determine the effects of topography and orography on temporal and spatial distribution of precipitation; and 4) to regionalize precipitation in the lake basin by using principal component and clustering analysis. The results will provide information 
for improving water resources management practices in the lake basin and increasing the effectiveness of the restoration plans.

\section{Materials and methods}

\subsection{Study area and local climate}

Lake Urmia plays an important socio-ecological role in the region (Khatami 2013). Over 6.5 million people live in the lake basin where the main sources of income are agriculture and industry. The lake's continuing decline threatens local hydrology and ecology and thus, the entire socioeconomy of the region. During recent years, the lake shrinking has been intensified by rapid agricultural development and related water and land use changes (Zarghami 2011; Hassanzadeh et al. 2012; Jalili et al. 2012; UNEP and GEAS 2012; Madani 2014; Haghighi and Kløve 2015; Madani et al. 2016). During recent dry periods in the lake basin, a rapid decrease in water level has been observed (Fathian et al. 2014). The lake bottom's salt exposure is expected to result in wind-blown salts, leading to soil degradation (Fathian et al. 2014) and possibly to salt storms with major health risk implications.

Lake Urmia Basin (coordinates: $35^{\circ} 40^{\prime}-3830^{\prime} \mathrm{N}$; $44^{\circ} 07^{\prime}-47^{\circ} 53^{\prime} \mathrm{E}$ ) covers $3.2 \%$ of the area of Iran, corresponding to about $52000 \mathrm{~km}^{2}$ (Fig. 1). The lake body and the neighboring plains (altitude 1280-2000 m amsl) encompass about 35\% of the total basin area surrounded by mountainous terrain, with mountain peaks to the west, south, and east of the lake reaching the maximum elevation of 3608, 3332, and $3850 \mathrm{~m}$ amsl, respectively (Jalili et al. 2012). Northwest Iran, like most of the country, is classified as arid to semi-arid (Ghasemi and Khalili 2008). Climate in the lake basin is mainly continental and characterized by cold winters and dry, temperate summers (Stevens et al. 2012). Mean annual precipitation in the basin is about $357 \mathrm{~mm}$. The 
mountainous terrain occupying much of the region is covered by snow during the winter receiving an annual total precipitation of about $380 \mathrm{~mm}$, while the lake and its adjacent plains receive 316 mm. The Zagros Mountains to the south-southwest and the Ararat Mountains in the far north of the basin have effects on the climate, but their orographic influence is minor compared with other rainfall-generating mechanisms (Raziei et al. 2008). Mean annual temperature throughout the basin is about $11^{\circ} \mathrm{C}$, ranging from $6.5^{\circ} \mathrm{C}$ in high latitudes to $13.5^{\circ} \mathrm{C}$ at lower latitudes. The lake moderates extreme temperatures and humidity in the region (Delju et al. 2013). The warmest and coldest months are July and January, respectively. The wet and humid season lasts from November to April/May and the summer season, with rare precipitation, is from May to October (UNEP and GEAS 2012). The annual potential evaporation in the area varies from $1050 \mathrm{~mm}$ in the north-east to $1550 \mathrm{~mm}$ in the south-west. (OWWMP 2011).

Fig. 1. Topography and location of Lake Urmia Basin in north-west Iran with available precipitation stations. Precipitation stations in red have less than 10 years, stations in green have 10-30 years, and stations in blue have more than 30 years of data.

\subsection{Data availability}

A set of 122 daily precipitation stations, operated by the Iran Water Resources Management Company, were used in this study (Fig. 1). Observations in this quite dense network are characterized by time series of different length and frequent missing data. The availability of data and length of observation for each station are illustrated in (Fig. 2). From the initial database, stations with at least a 30-year time span (1981-2010) and less than 30\% missing data were selected resulting in a sub-set of 50 stations. These are located within 3-290 km distance from each other and were used for the analysis of spatial structure of precipitation. 
The spatial structure of precipitation was first determined by spatial correlation analysis. This was done by calculating the Spearman rank correlation between pairwise combinations of rainfall stations. The correlation coefficients plotted against distance between stations give a general picture about the spatially varying rainfall fields and heterogeneity or homogeneity of the precipitation in the region (see e.g., Berndtsson 1987; Berndtsson and Niemczynowicz 1988). This analysis was done for daily, monthly, and annual total precipitation. Simultaneous zero values at both stations were eliminated from the calculations in order to reduce spurious correlation.

Fig. 2. Availability of data for all stations and length of the recorded data.

If only stations of equal time span and less than $10 \%$ missing data were to be selected for statistical analysis as suggested by Subramanya (1994), very few stations would have been selected, resulting in the loss of the representativeness of the selected stations. To avoid information loss by choosing a shortened time window and limited number of stations, a methodology that substitute the time series by its statistics was used (see e.g., Bharath and Srinivas 2015, Darand and Daneshvar 2014, Gocic and Trajkovic 2014, Martins et al. 2012, Ramos, 2001, Raziei et al. 2008 and, Winkler 2015). As a result, a new dataset comprising 122 stations was created and used for regionalization analysis and identification of precipitation patterns through principal component and cluster analysis.

The effect of atmospheric circulation over the lake basin precipitation was investigated by correlating the North Atlantic Oscillation (NAO) index with winter time total precipitation. Monthly values of the NAO index were taken from the Climate Research Unit, University of East Anglia (http://www.cru.uea.ac.uk/cru/data/nao/). 


\subsection{Statistical analysis}

Statistical analysis to identify the spatial pattern of precipitation in the region included PCA to reduce dimensionality of data and cluster analysis to classify sub-regions with similar precipitation characteristics. A total of 15 statistical descriptors for seasonal and annual total precipitation variation $\left(25^{\text {th }}\right.$ percentile, $75^{\text {th }}$ percentile, and coefficient of variation for annual and seasonal total precipitation) were calculated for each of the 122 selected time series. As input to the PCA, each time series is represented by its collection of 15 statistics and no longer by the observed data. The calculated statistics are listed in the first column of Table 1.

Prior to analysis, the adequacy of the created dataset to the PCA was evaluated using the KaiserMeyer-Olkin (KMO) test (Kaiser 1970). The KMO test value (Eq. 1) ranges from 0 to 1. Values greater than 0.5 and closer to 1 indicate that the selected dataset is suitable for structural analysis.

$K M O_{j}=\frac{\sum_{i \neq j} r_{i j}^{2}}{\sum_{i \neq j} r_{i j}^{2}+\sum_{i \neq j} u_{i j}^{2}}$

Where $r$ is the correlation matrix and $u$ is the partial covariance matrix.

\section{Principal component and cluster analysis}

PCA was used to identify spatial properties of precipitation statistics and homogeneous rainfall regions in the Lake Urmia Basin. PCA, a proven method for climatological regionalization, can be applied in six different modes based on the type and method of organizing the input data matrix (Richman 1986; Dinpashoh et al. 2004). The R-mode (data matrix with rows for the stations and columns for the 15 statistics), used in this study, aims to reduce the complexity of the variables (Martins et al. 2012; Gocic and Trajkovic 2014) and delineate the relationship between selected variables. Using the R-mode PCA, the selected 15 statistical descriptors were classified into groups with similar spatial distribution (Raziei et al. 2008). The number of principal components (PCs) to 
be retained for further analysis was decided based on the Scree plot and a simple rule of thumb. The Varimax orthogonal method was chosen to rotate the PCA-computed variables and search for spatial homogeneous clusters. With Varimax rotation the value of large loadings increases and the value of small loadings decreases (Soulé 1990; Dinpashoh et al. 2004; Raziei et al. 2008; Gocic and Trajkovic 2014).

To delineate different precipitation patterns and identify homogeneous groups in our dataset, the PCA results were subjected to cluster analysis. Cluster analysis is a useful technique to define similarity between groups and to classify them into clusters. All cluster analysis methods are based on minimizing the variance within the clusters. In this study, an agglomerative hierarchical cluster analysis based on Ward's method, the most common method in climate regionalization (Uvo 2003; Gocic and Trajkovic 2014; Sarhadi and Heydarizadeh 2014), was used to optimally find similar groups of stations in the Lake Urmia Basin. The hierarchical clustering method is based on the distance matrix (Darand and Daneshvar 2014). To measure the similarity of stations (distances), we used the Euclidean distance method (Eq. 2).

$$
d_{i j}=\sqrt{\sum_{k=1}^{m}\left(x_{i k}-x_{j k}\right)^{2}}
$$

Here $x_{i k}$ denotes the kth calculated statistic for station $i$ and $x_{j k}$ is the kth calculated statistic for station $j$. In all, $\mathrm{m}(=15)$ statistics are calculated for each station and $d_{i j}$ is the Euclidean distance between the two stations (Davis and Sampson 1986). Although, cluster analysis is a commonly used method, it sometimes needs subjective adjustments to find the most reasonable classification (Modarres and Sarhadi 2011). 


\section{Results and discussion}

\subsection{Rainfall characterization through statistical and principal component analysis}

Correlation with distance for annual, monthly, and daily time series for the 50 selected stations showed a clear spatial structure at all time scales (Fig. 3). In general, the spatial correlation increases as the time scale increases (daily to monthly to annual; Berndtsson 1987). There was a notable scatter in the data for Lake Urmia Basin, especially at the annual time scale, indicating a markedly different spatial variation in annual precipitation at various locations in the basin. Some of this scatter is evened out at the monthly time scale. There was marked small-scale variation at small distances, with even neighboring stations displaying a correlation of $0.5-0.6$, significant at a 90\% confidence level (Fig. 3c), which indicates spatially variable precipitation in the region. Differences between stations at small distances $(<50 \mathrm{~km})$ from each other can be attributed to random behavior of precipitation, together with errors and uncertainties in measurements (Bacchi and Kottegoda 1995). The structure of pairwise correlation plots suggests that the Lake Urmia basin is not a homogeneous region as regards precipitation. Further analysis on precipitation with PCA and clustering can explain the heterogeneity and identify homogeneous sub-regions.

Fig. 3. Spatial correlation between the 50 selected rainfall stations at: a) annual, b) monthly, and c) daily time scale. Correlation above 0.3 is significant at $90 \%$ confidence level

The KMO value was found to be 0.73 , indicating that the selected variable set is suitable for structural analysis. The 15 statistical descriptor set, comprising $25^{\text {th }}$ percentile, $75^{\text {th }}$ percentile, and coefficient of variation for annual and seasonal total precipitation, was subjected to PCA. The orthogonal Varimax rotation of first six PCs was used to improve the significance of influential 
variables and loads. The first six components after Varimax rotation explained 32, 17, 16, 12, 8, and $7 \%$ (Table 1) of total variance. Based on the Scree plot of eigenvalues (Fig. 4a) the first six PCs explaining $92 \%$ of total variance were retained for further analysis.

Fig. 4. Principal component analysis (PCA) graphs (a: Scree plot of eigenvalues; b: Biplot of variables)

Table 1. Summary of principal component analysis. RPC $=$ rotated principal component

\begin{tabular}{|c|c|c|c|c|c|c|}
\hline Variables & RPC1 & RPC2 & RPC3 & RPC4 & RPC5 & RPC6 \\
\hline Coefficient of variation of annual total precipitation & -0.04 & 0.08 & 0.05 & -0.92 & -0.21 & 0.21 \\
\hline Coefficient of variation of autumn total precipitation & 0.07 & 0.15 & 0.01 & -0.21 & $\underline{-0.93}$ & 0.14 \\
\hline Coefficient of variation of winter total precipitation & 0.3 & 0.05 & 0.09 & -0.15 & -0.15 & $\underline{0.91}$ \\
\hline Coefficient of variation of spring total precipitation & -0.03 & -0.05 & -0.11 & $\underline{-0.97}$ & -0.03 & -0.04 \\
\hline Coefficient of variation of summer total precipitation & 0.01 & $\underline{0.88}$ & 0.05 & -0.03 & -0.08 & 0.12 \\
\hline $25^{\text {th }}$ percentile of annual total precipitation & $\underline{-0.83}$ & -0.05 & 0.49 & 0.04 & 0.12 & -0.06 \\
\hline $25^{\text {th }}$ percentile variation of autumn total precipitation & $\underline{-0.78}$ & 0.03 & 0.21 & 0.04 & 0.48 & -0.05 \\
\hline $25^{\text {th }}$ percentile variation of winter total precipitation & $\underline{-0.94}$ & 0.14 & 0.04 & 0.01 & 0.03 & -0.21 \\
\hline $25^{\text {th }}$ percentile variation of spring total precipitation & -0.31 & -0.1 & $\underline{0.85}$ & 0.07 & 0.05 & -0.02 \\
\hline $25^{\text {th }}$ percentile variation of summer total precipitation & 0.19 & $\underline{-0.86}$ & 0.08 & -0.02 & 0.08 & 0.07 \\
\hline $75^{\text {th }}$ percentile of annual total precipitation & $\underline{-0.81}$ & -0.04 & 0.55 & -0.05 & -0.04 & -0.01 \\
\hline $75^{\text {th }}$ percentile variation of autumn total precipitation & $\underline{-0.88}$ & 0.18 & 0.22 & -0.08 & -0.11 & -0.12 \\
\hline $75^{\text {th }}$ percentile variation of winter total precipitation & $\underline{-0.95}$ & 0.19 & 0.07 & -0.06 & 0.03 & -0.07 \\
\hline $75^{\text {th }}$ percentile variation of spring total precipitation & -0.34 & -0.2 & $\underline{0.87}$ & 0.02 & -0.03 & 0.15 \\
\hline $75^{\text {th }}$ percentile variation of summer total precipitation & 0.19 & $\underline{-0.83}$ & 0.43 & 0.03 & -0.01 & 0.02 \\
\hline Standard deviation & 2.211 & 1.54 & 1.52 & 1.365 & 1.102 & 1.008 \\
\hline Percentage explained variance & 0.326 & 0.17 & 0.16 & 0.12 & 0.081 & 0.068 \\
\hline Cumulative percentage explained variance & 0.326 & 0.496 & 0.656 & 0.776 & 0.857 & 0.925 \\
\hline
\end{tabular}

Underscored values with high loadings (>0.70) indicate correlation between variables and RPCs.

The first rotated PC had high negative loadings for the $25^{\text {th }}$ and $75^{\text {th }}$ percentiles of annual, autumn, and winter total precipitation (Fig. 4b), indicating that precipitation variability is an important variable describing the spatial pattern of precipitation in the Lake Urmia Basin (Fig. 5, RPC1). High negative scores for the rotated first component cover the western and southern edges of the region while positive values cover the northern and northeastern parts. The spatial 
distribution of the first component scores is similar to the spatial distribution of winter and autumn $75^{\text {th }}$ and $25^{\text {th }}$ precipitation percentiles (Fig. 6, 75-winter and 25-autumn). The western and southern parts of the region receive higher amounts of precipitation during the cold season. Wet season precipitation in the whole region arises mostly because of westerly winds bearing moisture from the Mediterranean Sea (Dinpashoh et al. 2004). Topography controls part of the precipitation distribution in the region. Precipitation generally decreases from west to east. The mountainous terrain in the west and south cause precipitation fronts to deposit most of their moisture. Thus, they move to the eastern part of the basin carrying less moisture.

Fig. 5. Spatial distribution of PCA scores computed based on the loadings of the first six RPCs (rotated principal components)

The second PC explaining $17 \%$ of total variance is highly related with summer's total precipitation and $25^{\text {th }}$ and $75^{\text {th }}$ percentiles of summer precipitation (Fig. 4b) implying that summer precipitation is the second most important variable in the generation of heterogeneous regions in the Lake Urmia Basin. The high negative values of the second component scores cover the north and northeast (Fig. 5, RPC2). The spatial pattern of this component is consistent with the spatial distribution of summer precipitation's $25^{\text {th }}$ and $75^{\text {th }}$ percentiles (Fig. 6, 25-summer and 75summer). The region is characterized with more precipitation in summer due to the convective mechanism, local circulation, and lake effects. The high positive loading for the third PC distributed in western edges of the lake basin explains the importance of spring precipitation variability in the precipitation pattern of the region (Fig. 5, RPC3).

Annual and spring's total precipitation are the influential variables for the fourth component explaining $12 \%$ of total variance. The spatial distribution of this component illustrates 
a smaller variation throughout the region (Fig. 5, RPC4). The pattern suggests that spring and annual total precipitation have less effect on the spatial variation of the precipitation in the region. Contribution of the autumn precipitation in the region's precipitation pattern is defined by the fifth component explaining $8 \%$ of total variance (Fig. 5, RCP5). Winter's total precipitation variation having high positive values in south and southwest of the region is explained by the sixth component covering $7 \%$ of the total variance (Fig. 5 RCP6). Thus, the spatial pattern of the computed scores explains the importance of the contribution of seasonal precipitation variability in the spatial variation of precipitation regime.

Fig. 6. Spatial distribution of analyzed precipitation characteristics with identified groups. CV-is the coefficient of variation, 25 - represents $25^{\text {th }}$ percentiles of the annual and seasonal total precipitation, and 75 - represents $75^{\text {th }}$ percentiles of the annual and seasonal total precipitation.

\subsection{Delineation of homogeneous rainfall groups and corresponding precipitation}

\section{characteristics}

Considering the total variance explained by PCA components $(92 \%)$, the first six rotated PCs were subjected to cluster analysis and the spatial distribution of rotated PCs is shown in Fig. 5. The hierarchical cluster analysis identified three spatially homogeneous groups (Group-1, Group-2, and Group-3) for the Lake Urmia Basin (Fig. 7). Identified groups differ in precipitation characteristics and effects of physiography, land use, and climate throughout the region.

Fig. 7. Identified homogenouse groups of stations alnog with topography of the region. 
A general observation for all three groups is that most of the annual total precipitation falls during the wet seasons, autumn, winter, and spring (Fig. 8). The entire region receives the highest amount of precipitation in spring followed by winter and autumn.

Fig. 8. Statistical characteristics of identified clusters (a: coefficient of variation; $b: 25^{\text {th }}$ percentile; $c: 75^{\text {th }}$ percentile; and $d$ : total of the annual and seasonal precipitation)

Winter and autumn precipitation follows the Mediterranean pattern, linked to the NAO and westerly winds (Darand and Daneshvar 2014). The winter NAO influences the mean mid latitude storm track and brings rainfall to the Mediterranean region (López-Moreno et al. 2010; Mourato et al. 2010; Kelley et al. 2012). There is a significant negative correlation between wintertime NAO index and the winter precipitation anomaly (Fig. 9; correlation coefficient of -0.3 at $90 \%$ confidence level), confirming findings by (Ghasemi and Khalili 2008) who investigated the effect of atmospheric circulation patterns on winter precipitation over Iran. Moist air from the Black Sea and Atlantic Ocean also make minor contributions to rainfall in the Lake Urmia Basin (Alijani and Harman 1985; Khatami Mashhadi 2013). The topography and local relief of the basin influence precipitation-generating mechanisms and contribute to the precipitation distribution in the lake basin (Zeinoddini et al. 2014). Different land use types throughout the region, however, affect the spatial variation of precipitation by changes in the heat and moisture fluxes (Pielke et al. 2007)

Fig. 9. Winter precipitation anomaly and wintertime NAO

Group-1 includes 77 stations mostly located in central parts of the basin and extending from northwest to southeast following the north-south-oriented mountainous terrain (Fig. 7). 
Annual total precipitation in this group varies from 187 to $469 \mathrm{~mm}$ with an average of $335 \mathrm{~mm}$. The proportion of spring, winter, autumn, and summer precipitation in annual total precipitation is $38,31,27$, and 3\%, respectively (Fig. 8). Local precipitation is controlled by mid altitude topography and lake effects. Moist air by westerly winds decreases after crossing high western mountains in the western part of the region and causes less precipitation during winter in the central parts compared to the western and southern areas of the region. In spring, when the westerly winds weaken, the temperature in the region rises, the days get longer, and the heating of the ground gives rise to moisture in the region. Intensively irrigated agricultural lands in the region contribute to convective rainfall-generation systems through changes in surface albedo and moisture amount in the air (Pielke et al. 2007). Convective and frontal thunderstorms, along with the weakened effect of the westerlies, result in considerable amounts of precipitation in spring for central parts.

Stations within Group-2 cover the northern and northeastern parts of the Lake Urmia Basin (Fig. 7). Seasonal total precipitation in this group contributes to annual total precipitation by 45 , 22, 23, and $8 \%$ for spring, winter, autumn, and summer, respectively (Fig. 8). The westerly winds have minor effect on wintertime precipitation in this part of the region in contrast to the western and central parts (Alijani and Harman 1985; Jackson and Lockhart 1986). Cold, dry Siberian fronts crossing the Caspian Sea sometimes penetrate into the northeast parts of the region during the winter and have a negative effect on winter precipitation amounts (Alijani and Harman 1985). The most distinguished characteristic observed for Group-2 is summer precipitation. Summer is generally a dry season throughout Iran. But Lake Urmia Basin receives a small amount of precipitation during summer. The $75^{\text {th }}$ percentile of summer precipitation, a criterion in planning agricultural water demands during the growing season, has its highest values in northern and northeastern parts of the region ranging from 5 to $81 \mathrm{~mm}$. The summer precipitation pattern has previously been attributed to lake evaporation and the formation of low level clouds producing 
short-duration rainfall (Delju et al. 2013). The other distinct feature in this group is the contribution of spring precipitation to annual total precipitation. The amount is higher than the other two groups. This can be described by the influence of local and atmospheric circulation. The area in general, receives less amount of precipitation (319 $\mathrm{mm}$ average annual total precipitation) as compared to the southern and central parts of the region due to the deposited westerly winds, topography and land use. Eastern and northeastern parts of the lake have less agricultural and more industrialized lands in comparison to the central and western parts (OWWMP 2010). The land use type and pollutants affect the water cycle in the area and cause reduction in precipitation amounts (Huntington 2006).

Group-3 consists of stations in the western and southern edges of the basin located on mountain lee sides (Fig. 7). Spring, winter, autumn, and summer precipitation contribute to the total annual precipitation by $31,39,26$, and $2 \%$, respectively (Fig. 8 ). The average annual total precipitation in this region is about $515 \mathrm{~mm}$ and much larger than the regional average (364 $\mathrm{mm})$. The high mountains to the west prevent moisture-bearing air masses from moving across the region to central and eastern parts of the basin that consequently receives less precipitation than the regional average. Westerly winds, which are stronger during the winter, control precipitation distribution in southern and western edges. Summer precipitation in this sub-region has the least amount compared to the rest of the lake basin influenced by the distance from the lake.

The orientation of the identified clusters illustrates that precipitation pattern is largely controlled by orography and varies regionally with distance from the lake. The high mountains to the west prevent moisture-bearing air masses from moving across the region to central and eastern parts of the basin, including large parts of East Azerbaijan Province, which consequently receive less precipitation than the regional average. Rainfall amount increases with increasing distance from the lake shoreline in all directions. 


\section{Conclusions}

The spatial pattern of precipitation and its controlling factors in the Lake Urmia Basin were studied using PCA in association with cluster analysis. A dataset comprising 15 statistical descriptors for seasonal and annual total precipitation variation in 122 stations were forced into R-mode PCA. The analysis of all available precipitation data for the Lake Urmia Basin shows that the lake basin is a heterogeneous region as regards to precipitation. The analysis led to delineation of three homogeneous precipitation areas throughout the region. Seasonal precipitation variability $\left(25^{\text {th }}\right.$ and $75^{\text {th }}$ percentile variation of seasonal total precipitation) produces differences between clusters and characterizes the observed spatial patterns of precipitation. The $25^{\text {th }}$ and $75^{\text {th }}$ percentiles of annual, autumn, and winter total precipitation are the most significant contributing variables contributing in the first rotated PC, which explains about $32 \%$ of the total variance. The second rotated PC is mainly explained by variations in summer precipitation and $25^{\text {th }}$ and $75^{\text {th }}$ percentile variation of spring's total precipitation controls the variance in the third rotated PC.

The identified clusters showed that the precipitation pattern mostly follows the orography of the region. The high mountains to the west prevent moisture-bearing air masses from moving across the region to central and eastern parts of the basin. The west of the basin is the wettest subregion, receiving the highest amount of precipitation during winter. Winter precipitation contribution to annual total precipitation decreases moving eastward in the Lake Urmia Basin and spring rainfall-generating system becomes more effective in central and eastern sub-regions. Atmospheric and local circulation, agricultural and industrial land uses and, lake effect in rainfall generation have partial impact on the spatial distribution of precipitation in the region. Rainfall amount increases with increasing distance from the lake shoreline in all directions. Precipitation in the north and northeast parts of the basin is mostly affected by local circulation and orography. 
The amount of precipitation the eastern part receives during the summer is higher than the rest of the lake basin.

The study findings on precipitation distribution and its spatial variability within the Lake Urmia Basin are important and useful for accurate characterization of the basin's hydrology and for better water and agricultural planning in the region. 


\section{Figures}

Fig.1. Topography and location of Lake Urmia Basin in north-west Iran with available precipitation stations. Precipitation stations in red have less than 10 years, stations in green have 10-30 years, and stations in blue have more than 30 years of data.

Fig. 2. Availability of data for all stations and length of the recorded data.

Fig. 3. Spatial correlation between the 50 selected rainfall stations at: a) annual, b) monthly, and c) daily time scale. Correlation above 0.3 is significant at $90 \%$ confidence level

Fig. 4. Principal component analysis (PCA) graphs (a: Scree plot of eigenvalues; b: Biplot of variables)

Fig. 5. Spatial distribution of PCA scores computed based on the loadings of the first six RPCs (rotated principal components)

Fig. 6. Spatial distribution of analyzed precipitation characteristics with identified groups. CV- is the coefficient of variation, 25 - represents $25^{\text {th }}$ percentiles of the annual and seasonal total precipitation, and 75 - represents $75^{\text {th }}$ percentiles of the annual and seasonal total precipitation.

Fig. 7. Identified homogenouse groups of stations alnog with topography of the region.

Fig. 8. Statistical characteristics of identified clusters (a: coefficient of variation; $b: 25^{\text {th }}$ percentile; $c: 75^{\text {th }}$ percentile; and d: total of the annual and seasonal precipitation)

Fig. 9. Winter precipitation anomaly and wintertime NAO 


\section{REFERENCES}

Abatzopoulos T, Baxevanis A, Triantaphyllidis G, Criel G, Pador E, Van Stappen G, Sorgeloos P (2006) Quality evaluation of Artemia urmiana Gunther (Urmia Lake, Iran) with special emphasis on its particular cyst characteristics (International Study on Artemia LXIX). Aquaculture 254:442-454. doi: 10.1016/j.aquaculture.2005.11.007.

AghaKouchak A, Norouzi H, Madani K, Mirchi A, Azarderakhsh M, Nazemi A, Nasrollahi N, Farahmand A, Mehran A, Hasanzadeh E (2015) Aral Sea syndrome desiccates Lake Urmia: Call for action. J Great Lakes Res 41:307-311. doi: http://dx.doi.org/10.1016/j.jglr.2014.12.007.

Alijani B, Harman JR (1985) Synoptic climatology of precipitation in Iran. Ann Assoc Am Geogr 75:404-416.

Alipour H, Olya HGT (2015) Sustainable planning model toward reviving Lake Urmia. Int J Water Resour Dev 31:519-539. doi: 10.1080/07900627.2014.949636.

Babavalian H, Amoozegar MA, Zahraei S, Rohban R, Shakeri F, Moghaddam MM (2014) Comparison of Bacterial Biodiversity and Enzyme Production in Three Hypersaline Lakes; Urmia, Howz-Soltan and Aran-Bidgol. Indian J Microbiol 54:444-449. doi: 10.1007/s12088014-0481-9.

Bacchi B, Kottegoda NT (1995) Identification and calibration of spatial correlation patterns of rainfall. J Hydrol 165:311-348.

Berndtsson R (1987) On the use of cross-correlation analysis in studies of patterns of rainfall variability. J Hydrol 93:113-134.

Berndtsson R, Niemczynowicz J (1988) Spatial and temporal scales in rainfall analysis-Some aspects and future perspectives. J Hydrol 100:293-313.

Darand M, Daneshvar MRM (2014) Regionalization of Precipitation Regimes in Iran Using Principal Component Analysis and Hierarchical Clustering Analysis. Environ Process 1:517-532.

Davis JC, Sampson RJ (1986) Statistics and data analysis in geology, Wiley New York et al.

Delju A, Ceylan A, Piguet E, Rebetez M (2013) Observed climate variability and change in Urmia Lake Basin, Iran. Theor Appl Climatol 111:285-296.

Dinpashoh Y, Fakheri-Fard A, Moghaddam M, Jahanbakhsh S, Mirnia M (2004) Selection of variables for the purpose of regionalization of Iran's precipitation climate using multivariate methods. J Hydrol 297:109-123.

Fathian F, Morid S, Kahya E (2014) Identification of trends in hydrological and climatic variables in Urmia Lake basin, Iran. Theor Appl Climatol 119:443-464.

Ghasemi AR, Khalili D (2008) The association between regional and global atmospheric patterns and winter precipitation in Iran. Atmos Res 88:116-133.

Gocic M, Trajkovic S (2014) Spatio-temporal patterns of precipitation in Serbia. Theor Appl Climatol 117:419-431. 
Haghighi AT, Kløve B (2015) A sensitivity analysis of lake water level response to changes in climate and river regimes. Limnologica-Ecology and Management of Inland Waters 51:118-130.

Hamzekhani FG, Saghafian B, Araghinejad S (2016) Environmental management in Urmia Lake: thresholds approach. Int J Water Resour Dev 32:77-88. doi:

10.1080/07900627.2015.1024829.

Hassanzadeh E, Zarghami M, Hassanzadeh Y (2012) Determining the main factors in declining the Urmia Lake level by using system dynamics modeling. Water Resour Manage 26:129-145.

Huntington TG (2006) Evidence for intensification of the global water cycle: review and synthesis. J Hydrol 319:83-95.

Jackson P, Lockhart L (1986) The Cambridge History of Iran. , Cambridge Univ Pr.

Jalili S, Hamidi SA, Ghanbari RN (2016) Climate variability and anthropogenic effects on Lake Urmia water level fluctuations, northwestern Iran. Hydrol Sci J 61:1-11.

Jalili S, Kirchner I, Livingstone DM, Morid S (2012) The influence of large-scale atmospheric circulation weather types on variations in the water level of Lake Urmia, Iran. Int J Climatol 32:1990-1996.

Kaiser HF (1970) A second generation little jiffy. Psychometrika 35:401-415.

Kelley C, Ting M, Seager R, Kushnir Y (2012) The relative contributions of radiative forcing and internal climate variability to the late 20th Century winter drying of the Mediterranean region. Clim Dyn 38:2001-2015.

Khatami Mashhadi S (2013) Nonlinear Chaotic and Trend Analyses of Water Level at Urmia Lake, Iran. M.Sc. Thesis report: TVVR 13/5012, Lund University, Lund, Sweden.

López-Moreno JI, Vicente-Serrano SM, Angulo-Martínez M, Beguería S, Kenawy A (2010) Trends in daily precipitation on the northeastern Iberian Peninsula, 1955-2006. Int J Climatol 30:1026-1041.

Madani K (2014) Water management in Iran: what is causing the looming crisis? J Environ Stud Sci 4:315-328.

Madani K, AghaKouchak A, Mirchi A (2016) Iran's Socio-economic Drought: Challenges of a Water-Bankrupt Nation. Iranian Studies 49:997-1016. doi: 10.1080/00210862.2016.1259286.

Martins D, Raziei T, Paulo A, Pereira L (2012) Spatial and temporal variability of precipitation and drought in Portugal. Nat Hazards Earth Syst Sci 12:1493-1501.

Modarres R, Sarhadi A (2011) Statistically-based regionalization of rainfall climates of Iran. Glob Planet Chang 75:67-75.

Mourato S, Moreira M, Corte-Real J (2010) Interannual variability of precipitation distribution patterns in Southern Portugal. Int J Climatol 30:1784-1794.

OWWMP (2011) Iran Ministry of Energy's Office for Water and Wastewater MacroPlanning. Iran's comprehensive water resources plan. Meteorological Report 2385070-4420. 
OWWMP (2010) Iran Ministry of Energy's Office for Water and Wastewater Macro-

Planning. Iran's comprehensive water resources plan. Industrial Water Demand Report 23850702050.

Pielke R, Adegoke J, Beltran-Przekurat A, Hiemstra C, Lin J, Nair U, Niyogi D, Nobis T (2007) An overview of regional land-use and land-cover impacts on rainfall. Tellus B 59:587-601.

Raziei T, Bordi I, Pereira L (2008) A precipitation-based regionalization for Western Iran and regional drought variability. Hydrol Earth Syst Sci 12:1309-1321.

Richman MB (1986) Rotation of principal components. Journal of climatology 6:293-335.

Saikranthi K, Rao TN, Rajeevan M, Bhaskara Rao SV (2013) Identification and validation of homogeneous rainfall zones in India using correlation analysis. J Hydrometeorol 14:304-317.

Sarhadi A, Heydarizadeh M (2014) Regional frequency analysis and spatial pattern characterization of Dry Spells in Iran. Int J Climatol 34:835-848.

Sima S, Ahmadalipour A, Tajrishy M (2013) Mapping surface temperature in a hyper-saline lake and investigating the effect of temperature distribution on the lake evaporation. Remote Sens Environ 136:374-385.

Soltani S, Modarres R, Eslamian S (2007) The use of time series modeling for the determination of rainfall climates of Iran. Int J Climatol 27:819-829.

Soulé PT (1990) Spatial patterns of multiple drought types in the contiguous United States: A seasonal comparison. Clim Res 1:13-21.

Stevens LR, Djamali M, Andrieu-Ponel V, de Beaulieu J (2012) Hydroclimatic variations over the last two glacial/interglacial cycles at Lake Urmia, Iran. J Paleolimnol 47:645-660.

Subramanya K (1994) Engineering Hydrology, Tata McGraw-Hill.

Tabari H, Hosseinzadeh Talaee P (2011) Temporal variability of precipitation over Iran: 19662005. J Hydrol 396:313-320.

UNEP, GEAS (2012) The drying of Iran's Lake Urmia and its environmental consequences. J Environ Dev 2:127-138.

Uvo CB (2003) Analysis and regionalization of northern European winter precipitation based on its relationship with the North Atlantic Oscillation. Int J Climatol 23:1185-1194.

Vaheddoost B, Aksoy H (2016) Structural characteristics of annual precipitation in Lake Urmia basin. Theor Appl Climatol: doi:10.1007/s00704-016-1748-3.

Zarghami M (2011) Effective watershed management; case study of Urmia Lake, Iran. Lake Reserv Manage 27:87-94.

Zeinoddini M, Tofighi M, Bakhtiari A (2014) Assessment of 2DH and pseudo-3D modelling platforms in a large saline aquatic system: Lake Urmia, Iran. Hydrol Process 28:4953-4970. 
Zohrabi N, Bavani AM, Goodarzi E, Eslamian S (2014) Attribution of temperature and precipitation changes to greenhouse gases in northwest Iran. Quat Int 345:130-137. 